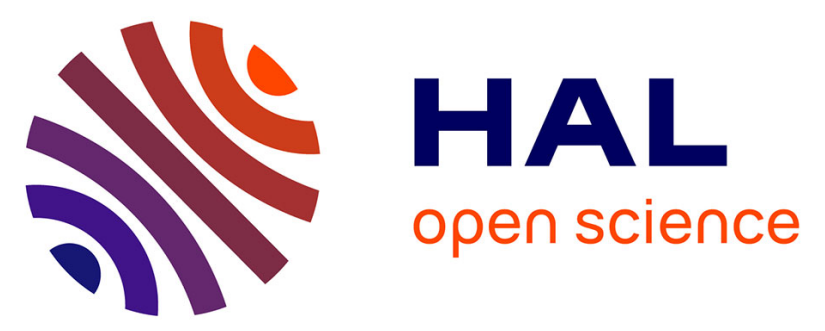

\title{
Purification of a laccase from Marasmius quercophilus induced with ferulic acid: reactivity towards natural and xenobiotic aromatic compounds
}

\author{
Anne Marie Farnet da Silva, S. Criquet, Mireille Cigna, Gérard Gil, Elisée
} Ferré

\section{To cite this version:}

Anne Marie Farnet da Silva, S. Criquet, Mireille Cigna, Gérard Gil, Elisée Ferré. Purification of a laccase from Marasmius quercophilus induced with ferulic acid: reactivity towards natural and xenobiotic aromatic compounds. Enzyme and Microbial Technology, 2004, 34 (6), pp.549-554. 10.1016/j.enzmictec.2003.11.021 . hal-02071810

\section{HAL Id: hal-02071810 https://hal.science/hal-02071810}

Submitted on 18 Mar 2019

HAL is a multi-disciplinary open access archive for the deposit and dissemination of scientific research documents, whether they are published or not. The documents may come from teaching and research institutions in France or abroad, or from public or private research centers.
L'archive ouverte pluridisciplinaire HAL, est destinée au dépôt et à la diffusion de documents scientifiques de niveau recherche, publiés ou non, émanant des établissements d'enseignement et de recherche français ou étrangers, des laboratoires publics ou privés. 


\title{
Purification of a laccase from Marasmius quercophilus induced with ferulic acid: reactivity towards natural and xenobiotic aromatic compounds
}

\author{
Anne-Marie Farnet ${ }^{\mathrm{a}, *}$, Stéven Criquet ${ }^{\mathrm{a}}$, Mireille Cigna ${ }^{\mathrm{a}}$, Gérard Gil ${ }^{\mathrm{b}}$, Elisée Ferré ${ }^{\mathrm{b}}$ \\ a Laboratoire de Microbiologie, Service 452, UMR CNRS 6116, Institut Méditerranéen d'Ecologie et de Paléoécologie, \\ Université d'Aix-Marseille III, Marseille, France \\ ${ }^{\mathrm{b}}$ Laboratoire de Chimie, Biologie et Radicaux Libres, Service 532, UMR CNRS 6517, Université d'Aix-Marseille III, Marseille, France
}

\begin{abstract}
In this study, we describe the biochemical features and the ability of a new laccase isoform from a Marasmius quercophilus strain collected on evergreen oak litter to transform various aromatic compounds. This laccase, induced with ferulic acid, exhibits interesting enzymatic properties, such as great thermal stability at 30 and $40^{\circ} \mathrm{C}(24 \mathrm{~h})$, no inhibition with EDTA, Cystein or SDS. These biochemical features are quite different from those observed with the laccase of another $M$. quercophilus strain collected in a different area of the South of France. Thus, this study shows the degree of variation in the properties of this enzymatic system within the same species. Furthermore we demonstrate that several natural aromatic compounds were transform leading to polymerization. The transformation of chlorophenols such as 2-chlorophenol, 2,4-dichlorophenol and 2,4,6-trichlorophenol is also observed without adding mediators (2,2'-azinobis(3-ethylbenzthiazoline-6-sulfonate) or 1-hydroxybenzotriazole) to the reaction mixture. Thus, the mediators used do not seem to extend the substrate range for this laccase under these experimental conditions.
\end{abstract}

Keywords: Aromatic compounds; Laccase; Mediators; White-rot fungi

\section{Introduction}

Marasmius quercophilus is a predominant basidiomycete in typical Mediterranean ecosystems such as evergreen (Quercus ilex L.) or cork oak (Quercus suber L.) litters. This white-rot fungus has been implicated in lignin biodegradation and thus plays an important ecological role since it contributes to the carbon recycling. Phenoloxidases, i.e. laccases, peroxidases or tyrosinases are the enzymatic systems which degrade lignin $[1,2]$. We have studied different laccases (EC 1.10.3.2.) produced by certain M. quercophilus strains collected in various areas in the south of France $[3,4]$. These studies attempt to determine whether the biochemical characteristics and the aromatic compound degradation potential of such a polymorphic enzymatic system may vary depending on different parameters: ecosystem, fungal strain or culture conditions. Finding a laccase which has a strong abil-

\footnotetext{
* Corresponding author. Tel.: +33-4-91-28-81-90; fax: +33-4-91-28-80-30

E-mail address: amfarnet@netscape.net (A.-M. Farnet).
}

ity to transform aromatic compounds is an important aim for biotechnological applications. Laccases have indeed aroused considerable interest in the last few years because of the reaction they catalyze. They reduce oxygen to water while oxidizing various phenolic compounds in a non-specific radical-based reaction. One of the applications is the degradation of chlorophenols which have been used extensively as pesticides and thus are now widely spread pollutants.

In this study, we described a new isoform of laccase produced by a $M$. quercophilus strain isolated from evergreen oak litter and which has been induced with ferulic acid. We also compared its biochemical characteristics with those of another isoform also induced with ferulic acid but produced by a $M$. quercophilus strain isolated from a cork oak litter. Furthermore, this new isoform has been tested on different phenolic compounds both with and without two mediators: 2,2'-azinobis(3-ethylbenzthiazoline-6-sulfonate) (ABTS) and 1-hydroxybenzotriazole (HBT), which have been extensively used to extend the range of substrates that can be oxidized and also to enhance the transformation of aromatic compounds [5]. 


\section{Materials and methods}

\subsection{Isolation of the strain}

M. quercophilus strain 19 was isolated from a part of the site of La Gardiole de Rians, Var, France (1 ha) using the rhizomorphic form of the fungus. A fungal cap culture was firstly made on a malt-agar medium, $20 \mathrm{gl}^{-1}$ (Bio Mérieux, Marcy l'Etoile, France) and chloramphenicol, $50 \mathrm{mgl}^{-1}$ (Sigma). Secondly, the pure mycelial culture obtained was used to inoculate an agar medium (whole wheat flour, $20 \mathrm{gl}^{-1}$ ) which favours rhizomorph production. Then one rhizomorph was used to inoculate a malt-agar plate to obtain a pure dicaryotic culture.

\subsection{Culture conditions}

Precultures were performed in $200 \mathrm{ml}$ Erlenmeyer flasks containing $50 \mathrm{ml}$ of malt extract medium $\left(20 \mathrm{~g} \mathrm{l}^{-1}\right)$ in static conditions at $28^{\circ} \mathrm{C}$. They were inoculated with a plug of agar cultures $\left(15 \mathrm{gl}^{-1}\right)$ with malt extract $\left(20 \mathrm{gl}^{-1}\right)$. These liquid precultures were used to inoculate two 3000-ml Erlenmeyer flasks with $800 \mathrm{ml}$ of malt extract medium $\left(20 \mathrm{gl}^{-1}\right)$; Tween $80,0.05 \%$; $\mathrm{CuSO}_{4}, 5 \mathrm{mgl}^{-1}$; ferulic acid, $500 \mathrm{mg} \mathrm{l}^{-1}$. They were incubated at $28^{\circ} \mathrm{C}$ for 12 days under an axial shaking. Enzyme activity was measured by following the oxidation of syringaldazine [ $N, N^{\prime}$-bis-(3,5-dimethoxy-4-hydroxybenzylidene)hydrazine] that leads to its quinone $\left(\varepsilon^{\mathrm{M}}: 6.510^{4} \mathrm{M}^{-1} \mathrm{~cm}^{-1}\right)$ at $525 \mathrm{~nm}$ [6] on a spectrophotometer Kontron Uvikon 860. The assay contained $100 \mu \mathrm{l}$ of the culture medium, $2.5 \mathrm{ml}$ of phosphate buffer $0.1 \mathrm{M}, \mathrm{pH} 5.7$ and $10 \mu \mathrm{l}$ of syringaldazine $0.6 \%$ $(\mathrm{w} / \mathrm{v})$, diluted in methanol. The blank consisted of $100 \mu \mathrm{l}$ of the culture medium and $2.5 \mathrm{ml}$ of the same phosphate buffer.

\subsection{Purification of the two laccase isozymes}

Cultures were filtered on a glass microfiber filter GF/D, $2.7 \mu \mathrm{m}$ (Whatman, England). Then, the filtered culture medium was concentrated in dialysis tubes rated at $12 \mathrm{kDa}$ (32 mm diameter, Poly Labo) using polyethyleneglycol. The samples from the different tubes were pooled using a phosphate buffer $20 \mathrm{mM}, \mathrm{pH} 5.7$ in a final volume of $15 \mathrm{ml}$. This sample was then loaded on a Mono Q column. A step gradient system of $\mathrm{NaCl}$ in Tris- $\mathrm{HCl}$ buffer $10 \mathrm{mM}$ pH 6 $(0,0.2,0.4,1 \mathrm{M})$ was used to elute active fractions. Laccase activity was detected using syringaldazine. The active fractions eluted as one peak were pooled and concentrated on an ultrafiltration cell, Model 8200 (Amicon, Beverly, USA) till the volume reached $5 \mathrm{ml}$. The membrane used (Amicon), was rated at $10 \mathrm{MW}(10 \mathrm{kDa})$ cut-off. This membrane was rinsed with an additional volume of $1 \mathrm{ml}$ of acetate buffer, $0.1 \mathrm{M}, \mathrm{pH} 4$ to remove any bound laccases from its surface.

\subsection{Effects of $\mathrm{pH}$ and temperature on laccase activity}

Laccase activity was detected as previously described using $15 \mu \mathrm{l}$ of the purified fraction. Acetate buffer $0.1 \mathrm{M}$ was used for $\mathrm{pH}$ range from 4 to 5 and phosphate buffer $0.1 \mathrm{M}$ for $\mathrm{pH}$ range from 5.7 to 8 . The optimum temperature for laccase activity was determined using $15 \mu \mathrm{l}$ of the purified fraction in acetate buffer $0.1 \mathrm{M} \mathrm{pH} 4.5$. Seven temperatures were tested: $30,40,50,60,70,80,90^{\circ} \mathrm{C}$. The thermal stability of laccase activity was studied using the temperatures mentioned above and after several incubation times $(1,2$, $3,5,7,9,24$ and $36 \mathrm{~h}$ ). Laccase activity was also measured using $15 \mu$ l of the purified fraction.

\subsection{Effects of inhibitors on laccase activity}

Laccase activity was measured using $15 \mu l$ of the purified enzyme in acetate buffer $0.1 \mathrm{M}, \mathrm{pH} 4.5$ with ABTS $100 \mu \mathrm{M}$ as the substrate. The inhibitors used at a final concentration of $1 \mathrm{mM}$ were: sodium azide, EDTA, cystein, and sodium diethyldithiocarbamate (DDC). All the chemical products were purchased from Sigma.

\subsection{Determination of kinetic parameters}

Syringaldazine and ABTS were used as substrates for the determination of the $V_{\mathrm{m}}$ and $K_{\mathrm{m}}$ which were calculated using the Lineweaver-Burk transformation of Michaelis-Menten equation. The concentrations ranged from 0.5 to $50 \mu \mathrm{M}$ and from 1 to $10 \mu \mathrm{M}$ for ABTS and syringaldazine respectively in acetate buffer $0.1 \mathrm{M} \mathrm{pH} 4.5$.

\subsection{Electrophoresis analysis}

Sodium dodecyl sulfate (SDS)-polyacrylamide gel electrophoresis (PAGE) were carried out according to Laemmli [7] using $4 \%$ stacking gel and $12 \%$ separating gel at $220 \mathrm{~V}$ with the Mini-Protean II electrophoresis cell (Bio-Rad). Molecular weight of the laccase isozyme was determined using high range molecular weight prestained standard (Bio-Rad). Protein band was revealed using the Coomassie blue standard method. For laccase activity staining, acetate buffer, $0.1 \mathrm{M}, \mathrm{pH} 4.5$, with syringaldazine $0.1 \%$ or $p$-phenylenediamine $0.1 \%$ was used as the staining solution.

\subsection{HPLC analysis of aromatic compound degradation}

HPLC system was equipped with a C18 column (Merck, $4.6 \mathrm{~mm} \times 250 \mathrm{~mm})$ in the following gradient system: solvent A, water/0.1\% trifluoro acetic acid/methanol 90/10 (v/v), solvent B water/0.1\% trifluoro acetic acid/methanol $95 / 5(\mathrm{v} / \mathrm{v})$, gradient $=0-30 \mathrm{~min} \mathrm{~A} 100 \%$ to $\mathrm{B} 100 \%$, $30-40 \mathrm{~min}$ B $100 \%$ (flow rate $1 \mathrm{ml} \mathrm{min}^{-1}$ ). The aromatic compound degradation was assayed using a reaction mixture $(10 \mathrm{ml})$ containing ABTS or HBT $1 \mathrm{mM}$, aromatic 
compound $1000 \mathrm{mg}^{-1}$ and $5 \mathrm{U}$ of laccase in acetate buffer $0.1 \mathrm{M} \mathrm{pH}$ 4.5. The aromatic compounds used were: catechin, ellagic acid, ferulic acid, gallic acid, protocatecuic acid, $p$-hydroxybenzoic acid, vanillic acid, veratryl alcohol, 2-chlorophenol (2-CP), 2,4-dichlorophenol (2,4-DCP), 2,4,6-trichlorophenol (2,4,6-TCP) and pentachlorophenol (PCP). All the aromatic compounds were purchased from Sigma. The same reaction was performed without mediators. Controls were also realized using only ABTS or HBT with laccase and using ABTS or HBT with the aromatic compound but without laccase. Samples were collected at $0,2,4$ and $48 \mathrm{~h}$ and $30 \mu \mathrm{l}$ of each sample was injected in the HPLC system. $P$-hydroxybenzoic acid was used as reference in each injection.

\section{Results}

The production of the induced isoform was observed on SDS-PAGE after a 5-day incubation and the maximum global laccase activity was obtained after a 12-day incubation (Fig. 1). The laccase isozymes in the culture supernatant were separated by SDS-PAGE: three isoforms were stained with $p$-phenylenediamine as previously described [2]. The isoform with the lowest molecular weight was then purified using a Mono Q chromatography column (Fig. 2). This purification step allowed us to obtain a single band on the gel using syringaldazine as the substrate. Under denaturing conditions we also observed a major protein band with a molecular weight of about $60 \mathrm{kDa}$ (Scheme 1).

The effect of $\mathrm{pH}$ (values ranging from 3 to 8) was examined on laccase activity. The $\mathrm{pH}$ optimum of the induced laccase was 4 using ABTS and 4.5 using syringaldazine (Fig. 3). The maximum activity was obtained at $80^{\circ} \mathrm{C}$ with these two substrates. The thermal stability of this enzyme was greatest at 30 and $40{ }^{\circ} \mathrm{C}(100 \%$ of the maximal activity remained after a $24 \mathrm{~h}$ incubation) while the enzymatic activity quickly decreased (after a 1-h incubation) however high temperatures tested $\left(50,60,70,80,90^{\circ} \mathrm{C}\right)$. Furthermore, we observed an increase in enzymatic activity from 1250 to $2330 \mathrm{U}^{-1}$ for $30^{\circ} \mathrm{C}$ and from 1300 to $2700 \mathrm{U}^{-1}$ for $40^{\circ} \mathrm{C}$.

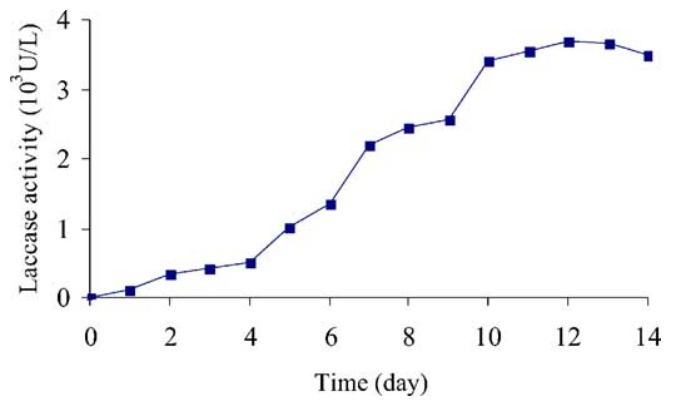

Fig. 1. Time course of total laccase activity $\left(\mathrm{Ul}^{-1}\right)$ in liquid cultures with malt extract medium $\left(20 \mathrm{gl}^{-1}\right)$, Tween $80(0.05 \%), \mathrm{CuSO}_{4}\left(5 \mathrm{mg} \mathrm{l}^{-1}\right)$ and ferulic acid $\left(500 \mathrm{mg}^{-1}\right)$ at $28^{\circ} \mathrm{C}$. All the standard deviations were below $3 \%$.

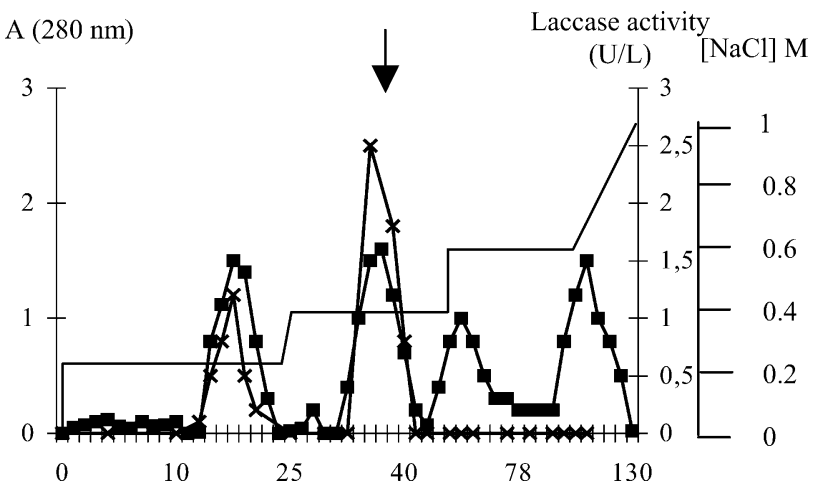

Fig. 2. Purification profile of the laccase induced with ferulic acid from strain 19 using a step gradient of $\mathrm{NaCl}$ : $(\times)$ laccase activity $\left(\mathrm{Ul}^{-1}\right),(\boldsymbol{\square})$ absorption at $280 \mathrm{~nm}$. The arrow indicates the peak of the induced isoform.

The first values (1250 and $1300 \mathrm{Ul}^{-1}$ ) are the basal laccase activities at room temperature. The kinetic parameters $V_{\mathrm{m}}$ and $K_{\mathrm{m}}$ were $2 \mathrm{mM} \mathrm{min}^{-1}, 4.2 \mu \mathrm{M}$ for syringaldazine and $3.3 \mathrm{mM} \mathrm{min}^{-1}, 11.3 \mu \mathrm{M}$ for ABTS. Laccase activity was not affected by EDTA or cystein as inhibitors while strong inhibition was observed with azide. With DDC, first a decrease in absorption was observed for $11 \mathrm{~min}$, followed by an increase for four more minutes and the absorption finally stabilized for the last $15 \mathrm{~min}$ of the experiment (Fig. 4).

All the natural aromatic compounds, gallic acid, tannic acid, protocatecuic acid and vanillic acid were transformed with or without the addition of mediators. For gallic acid, ferulic acid tannic acid or vanillic acid, several new peaks were obtained (Fig. 5) while the transformation of protocatecuic acid led to a single major peak. All these newly transformed compounds eluted after a longer elution time than the initial peaks.

The transformation of chlorophenols was efficient for 2-CP, 2,4-DP and 2,4,6-TCP. A decrease of about 50\% of the initial absorption was observed for 2-CP with the enzyme alone and with 2,4-DP with the enzyme added

103

77

50

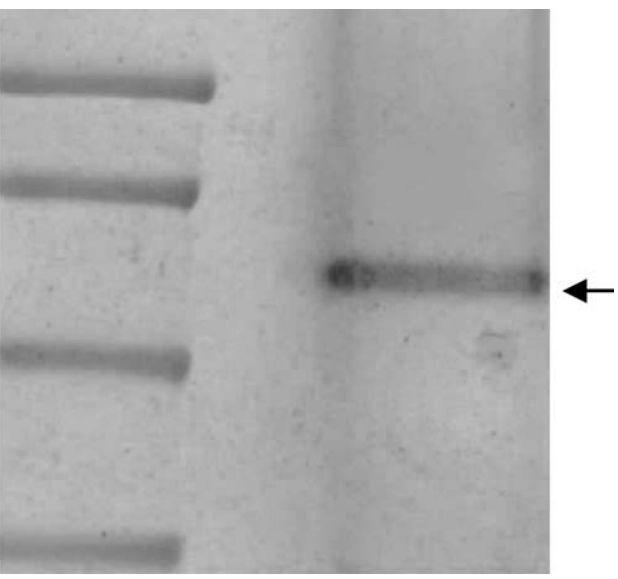

Scheme 1. The profile of the purified laccase induced with ferulic acid from strain 19 on a SDS-PAGE (low molecular weight markers $(\mathrm{kDa})$ on the left line). 


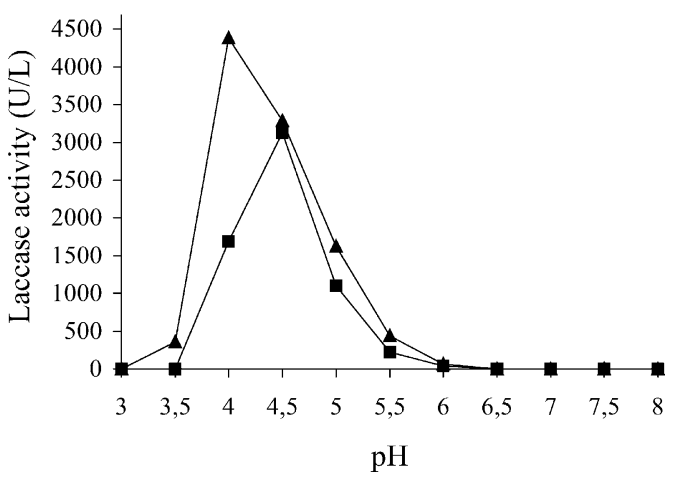

Fig. 3. The effect of $\mathrm{pH}$ on the induced laccase activity $\left(\mathrm{Ul}^{-1}\right)$ using ABTS $(\boldsymbol{\square})$ or syringaldazine $(\boldsymbol{\Delta})$. All the standard deviations were below $3 \%$.

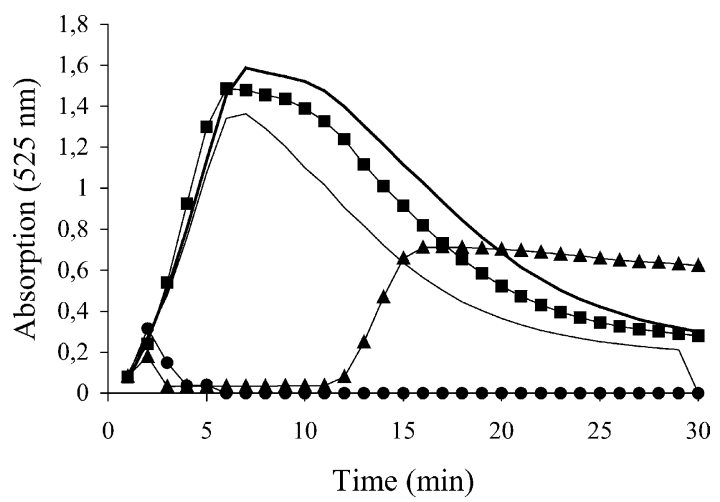

Fig. 4. The effect of inhibitors on the production of the quinone of syringaldazine at $525 \mathrm{~nm}$ : (-) without inhibitor, (ם) with EDTA, (一) with Cystein, $(\mathbf{O})$ with sodium azide, $(\mathbf{\Delta})$ with DDC. All the standard deviations were below $3 \%$.

with ABTS. Furthermore, with 2,4,6-TCP the decrease in initial absorption was stronger (about 23\%) with or without mediators. Moreover, for these three chlorophenols, we detected several peaks which eluted after longer retention times. We did not observe the transformation of pen-

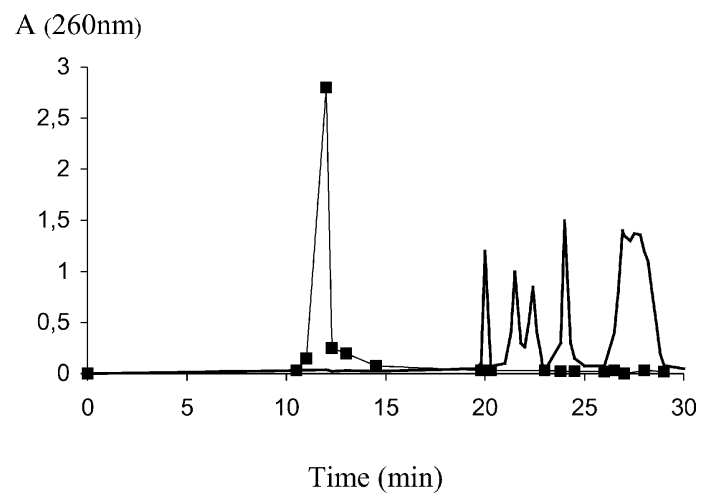

Fig. 5. The analysis of the transformation of vanillic acid with the induced

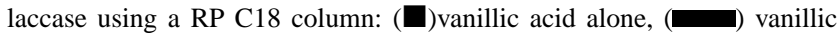
acid added with the induced laccase.

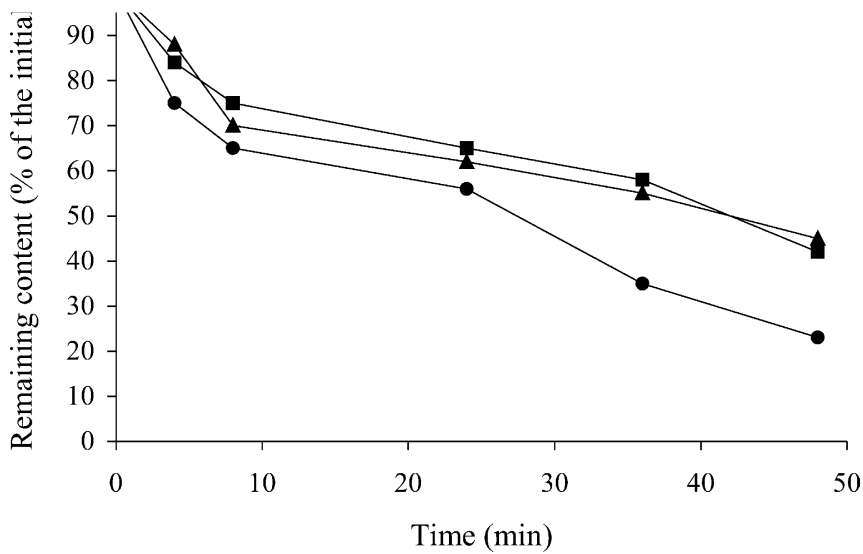

Fig. 6. Transformation of 2-CP, 2,4-DCP and 2,4,6-TCP through time. The results are expressed as the percentage of remaining absorption of

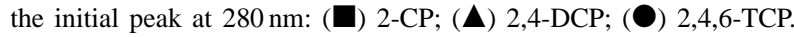

tachlorophenol whatever the experimental conditions used (Fig. 6).

\section{Discussion}

Previous studies have allowed us to purify various isoforms of laccases produced by strains isolated from evergreen oak [3] or cork oak litter [4]. We have shown that the strains isolated from evergreen oak litter exhibited similar laccase patterns under ferulic acid induction: three isoforms were observed [2]. We have already purified and described the two laccase isoforms with higher molecular weights [3]. In this study we wanted to characterize the third laccase isoform induced with ferulic acid from a M. quercophilus strain isolated from a $Q$. ilex $\mathrm{L}$. litter. A similar experiment of induction with ferulic acid [4] has been realized with a M. quercophilus strain collected from a cork oak litter $(Q$. suber L.). The biochemical characteristics of this two laccase isoenzymes induced with ferulic acid differ in various ways: optimum $\mathrm{pH}$, thermal stability and $V_{\mathrm{m}}$ and $K_{\mathrm{m}}$ values (Table 1). The optimum $\mathrm{pH}$ for laccase activities is usually low, ranging from 3.0 to 4.5 [8] but great differences have been observed between the two isoforms using ABTS and syringaldazine as the substrates. Furthermore, stability at $40^{\circ} \mathrm{C}$ was significantly greater for the laccase from strain 19 ( $48 \mathrm{~h}$ instead of $7 \mathrm{~h}$ ). Decreases in thermal stability of laccases at higher temperatures have already been described in several studies [9]. The optimum temperature found $\left(80^{\circ} \mathrm{C}\right)$ was similar for both laccases from strains 19 and C7. Laccases can exhibit very different optimum temperatures from $30^{\circ} \mathrm{C}$ for example with the hyphomycete Chalara paradoxa [10] to $80^{\circ} \mathrm{C}$ with basidiomycete PM1 [11]. The $V_{\mathrm{m}}$ and $K_{\mathrm{m}}$ values differed considerably from one isoform to another. The values found for strain 19 were close to those observed for other laccases from white-rot fungi such as Trametes 
Table 1

The biochemical features of the laccases induced with ferulic acid from strains C7 and 19 of the white-rot fungus Marasmius quercophilus

\begin{tabular}{lcc}
\hline & Strain C7 & Strain 19 \\
\hline Molecular weight $(\mathrm{kDa})$ & 65 & 60 \\
pH ABTS & 2.6 & 4 \\
pH syringaldazine & 6.2 & 4.5 \\
$V_{\mathrm{m}}$ ABTS $\left(\mu \mathrm{M} \mathrm{min}{ }^{-1}\right)$ & $1.1^{\mathrm{a}}$ & 3.3 \\
$K_{\mathrm{m}}$ ABTS $(\mathrm{mM})$ & 7.7 & $113 \times 10^{-3}$ \\
$V_{\mathrm{m}}$ syringaldazine $\left(\mu \mathrm{M} \min ^{-1}\right)$ & $7.8 \times 10^{-2}$ & 2 \\
$K_{\mathrm{m}}$ syringaldazine $(\mathrm{mM})$ & $50^{\mathrm{a}}$ & $4.2 \times 10^{-3}$ \\
Optimum temperature $\left({ }^{\circ} \mathrm{C}\right)$ & $80^{\mathrm{a}}$ & 80 \\
Thermal stability at $40^{\circ} \mathrm{C}$ & ${\text { After } 7 \mathrm{~h}^{\mathrm{a}}}^{\circ}$ & After $48 \mathrm{~h}$ \\
$\quad(50 \%$ activity remaining) & & EDTA, Cystein \\
No inhibition & $\mathrm{EDTA}^{\mathrm{a}}$ & SDS \\
\hline
\end{tabular}

${ }^{\text {a }}$ Data from Farnet et al. [4].

pubescens [12] or Ganoderma lucidum [13]. We also observed that EDTA and cystein did not inhibit laccase from strain 19 although the absence of inhibition was shown only when EDTA was added to the laccase from strain C7. Furthermore, the staining of SDS-PAGE with syringaldazine was possible, which may suggest the absence of inhibition of laccase with SDS for the concentration used. These properties are particularly interesting since other studies have demonstrated a loss of activity of this enzyme with similar inhibitor concentrations when EDTA, cystein or SDS were used as the inhibiting agents. When compared to the other isoforms of laccases previously purified [3], biochemical differences were also pointed out: those isoforms exhibited different optimum $\mathrm{pHs}$ for laccase activity with syringaldazine as the substrate (pH 5; $\mathrm{pH} 5$ and 6) and also a greater thermal stability of laccase activities. Thus, this study shows the great variations of the biochemical properties of laccases produced by a single fungal species.

The transformation with laccase of most of the natural aromatic compounds tested showed several new peaks with hydrophobic properties (longer elution times). This suggests a polymerization of these compounds which was probably due to the formation of radicals by the laccase. Few studies have sought to identify the by-products of laccase transformation. Recently, Carunchio et al. [14] have described dimerization of ferulic acid with a laccase. In this study, the authors have identified three intermediates which react to form six different dimers. They separated two major by-products of oligomerization, which allowed them to identify these two compounds using mass spectrometry. It seems that the laccase from M. quercophilus forms many different compounds from gallic acid, ferulic acid and tannic acid. This result is observed with or without mediators thus these non-specific reactions are not due to the action of oxidized mediators alone. The radicals formed with laccase seem to interact in different ways, leading to various polymerized compounds.

The transformed chlorophenols tested have chlorine atoms in ortho or para position. The meta-substituted com- pounds have been found not to be easily transformed [15]. Indeed, dechlorination of halogenated compounds has been reported with laccase in ortho or para positions with respect to the hydroxyl group of the same ring [16]. In this study, the transformation of chlorophenols has shown that the order of reactivity of the induced laccase was 2,4,6-TCP > 2,4-DCP > 2-CP. This is in correlation with the study of Itoh et al. [17] which have described the action of a laccase towards several different chlorophenols. Thus, the reactivity of laccase increases with the number of chlorine on the cycle. This may be better explained by the increase in proton acidity of the hydroxyl group because of the chlorine atoms than by a higher specificity of laccase for this chemical compound. The formation of the radical may be favored by the electroattractive property of the chlorine atoms. With chloroaromatic, we have also observed new several peaks at the end of the elution gradient that suggests an oligomerization as described by Leontievsky et al. [18]. For PCP, Aiken and Logan [19] have reported its biodegradation with the white-rot fungus Phanerochaete chrysosporium. Nevertheless, few studies have described its transformation by white-rot fungus polyphenoloxidases.

In further studies, we will attempt to assess the transformation of aromatic compounds using the supernatant of a culture from $M$. quercophilus. This would allowed us to evaluate the potential effect of other enzymes such as peroxidases which are also produced by this fungus. The synergistic action of both phenoloxidases may improve the biotransformation of such recalcitrant compounds.

\section{References}

[1] Tagger S, Périssol C, Gil G, Vogt G, Le Petit J. Phenoloxidases of the white-rot fungus Marasmius quercophilus isolated from an evergreen oak litter (Quercus ilex L.). Enzyme Microbial Technol 1998;23:372-9.

[2] Farnet AM, Tagger S, Le Petit J. Effects of copper and aromatic inducers on the laccases of the white rot fungus Marasmius quercophilus. In: Comptes Rendus de l'Académie des Sciences, Paris. Sciences de la Vie/Life Sciences 1999;322:499-503.

[3] Farnet AM, Criquet S, Tagger S, Gil G, Le Petit J. Purification, partial characterization and reactivity with aromatic compounds of two laccases from Marasmius quercophilus strain 17. Can J Microbiol 2000;46:1-6.

[4] Farnet AM, Criquet S, Pocachard E, Gil G, Ferré E. Purification of a new isoform of laccase from a Marasmius quercophilus strain isolated from a cork oak litter (Quercus ilex L.). Mycologia 2002;94:735-40.

[5] Bourbonnais R, Leech D, Paice MG. Electrochemical analysis of the interactions of laccase mediators with lignin model compounds. Biochem Biophys Acta 1998;1379:381-90.

[6] Harkin JM, Larsen MJ, Obst JR. Use of syringaldazine for detection of laccase in sporophores of wood rotting fungi. Mycologia 1974;66:469-76.

[7] Laemmli UK. Cleavage of structural proteins during the assembly of the head of bacteriophage T4. Nature 1970;227:680-5.

[8] Heinzkill M, Bech L, Halkier T, Schneider P, Anke T. Characterization of laccases from a wood-rotting fungi (family Coprinaceae). Appl Environmental Microbiol 1998;64:1601-6.

[9] Nyanhongo GS, Gomes J, Gübitz G, Zvauya R, Read JS, Steiner W. Production of laccase by a newly isolated strain of Trametes modesta. Bioresource Technol 2002;84:259-63. 
[10] Robles A, Lucas R, Martinez-Canamero M, Ben Omar N, Perez R, Galvez A. Characterisation of laccase activity produced by the hyphomycete Chalara (syn. Thielaviopsis) paradoxa $\mathrm{CH} 32$. Enzyme Microbial Technol 2002;31:516-22.

[11] Coll PM, Tabernero C, Santamaria R, Perez P. Characterization and structural analysis of the laccase I gene from the newly isolated ligninolytic basidiomycete PM1 (CECT 2971). Appl Environ Microbiol 1993;59:4129-35.

[12] Galhaup C, Goller S, Peterbauer CK, Strauss J, Haltrich D. Characterization of the major laccase isoenzyme from Trametes pubescens and regulation of its synthesis by metal ions. Microbiology 2002;148:2159-69.

[13] Ko E-M, Leem Y-E, Choi HT. Purifiaction and characterization of laccase isozymes from the white-rot basidiomycete Ganoderma lucidum. Appl Microbiol Biotechnol 2001;57:98102.

[14] Carunchio F, Crescenzi C, Girelli A-M, Messina A, Tarola A-M. Oxidation of ferulic acid by laccase: identification of the products and inhibitory effects of some peptides. Talanta 2001;55:189_ 200.

[15] Filazzola MT, Sannino F, Rao MA, Gianfreda L. Effect of various pollutants and soil-like constituents on laccase from Cerrena unicolor. J Environ Quality 1999;28:1929-38.

[16] Schultz A, Jonas U, Hammer E, Schauer F. Dehalogenation of chlorinated hydroxybiphenyls by fungal laccase. Appl Environ Microbiol 2001;67:4377-81.

[17] Itoh K, Fujita K, Suyama K, Yamamoto H. Phenolic acids affect transformations of chlorophenols by a Coriolus versicolor laccase. Soil Biol Biochem 2000;32:85-91.

[18] Leontievsky AA, Myasoedova NM, Baskunov BP, Golovleva LA, Bucke C, Evans CS. Transformation of 2,4,6-trochlorophenol by free and immobilized fungal laccase. Appl Microbiol Biotechnol 2001;57:85-91.

[19] Aiken BS, Logan B. Degradation of pentachlorophenol by the white-rot fungus Phanerochaete chrysosporium grown in ammonium lignosulfonate media. Biodegradation 1996;7:175-82. 